Maria Juliana Moura-Correa ${ }^{a^{*}}$

Ariane Leites Larentis ${ }^{b^{*}}$

\section{Exposição ao benzeno no trabalho e seus efeitos à saúde}

\author{
Exposure to benzene at work and its effects on health
}

\begin{abstract}
${ }^{a}$ Universidade Federal da Bahia, Instituto de Saúde Coletiva, Programa Integrado em Saúde Ambiental e do Trabalhador. Salvador, BA, Brasil.

${ }^{\mathrm{b}}$ Fundação Oswaldo Cruz (Fiocruz), Escola Nacional de Saúde Pública Sergio Arouca (ENSP), Centro de Estudos da Saúde do Trabalhador e Ecologia Humana (CESTEH). Rio de Janeiro, RJ, Brasil.
\end{abstract}

*Editoras convidadas

\section{Contato}

Maria Juliana Moura Corrêa

E-mail

mjulianamc@gmail.com
Este suplemento do volume 42 da Revista Brasileira de Saúde Ocupacional (RBSO) apresenta o Dossiê Temático "Exposição ocupacional ao benzeno na cadeia de distribuição e revenda de combustíveis no Brasil", que traz para o debate produção elaborada a partir do aprendizado coletivo e da experiência de grupo de pesquisadores, técnicos e gestores do Sistema Único de Saúde (SUS), e de autores convidados, que atuam nas questões relacionadas com a exposição ao benzeno no trabalho, sobretudo por meio das ações dos Centros de Referência em Saúde do Trabalhador (Cerest). Essa produção é, portanto, resultado de estudos, da análise de registros históricos e normativos, e das práticas dos serviços públicos de saúde. Com essa conformação e diferentes perspectivas, são apresentadas contribuições de/para a pesquisa, abordando questões de organização dos trabalhadores e de seus ambientes de trabalho, das ações de vigilância do SUS (por meio da divulgação dos resultados de estudos de diferentes regiões do país), do fazer dos serviços especializados em Saúde do Trabalhador, que, junto com os registros da experiência de exposição dos trabalhadores do ramo, compõem as lições no campo da exposição ocupacional ao benzeno no Brasil.

O foco central deste dossiê foi agregar novos conhecimentos, que integram saberes interdisciplinares sobre os riscos, o monitoramento e as consequências da exposição ocupacional ao benzeno, com o objetivo de qualificar a investigação em ambientes de trabalho dos postos de revenda de combustíveis (PRC) e, com isso, subsidiar medidas e programas de proteção à saúde dos trabalhadores. A importância desta publicação deve-se à complexidade e gravidade dessa exposição e aos seus efeitos nocivos à saúde, bem como às lacunas que ainda persistem no campo da pesquisa $\mathrm{e}$ do registro da história brasileira sobre o assunto.

No Brasil, estudo de Costa e Goldbaum ${ }^{1}$ divide a experiência brasileira de exposição ao benzeno em quatro períodos. No primeiro ciclo, de 1930 a 1960, surgem as primeiras iniciativas de controle da exposição ao benzeno, com legislação restritiva à exposição publicada em 1932, proibindo as atividades perigosas e insalubres para mulheres, incluindo aquelas que envolvem o benzeno, e posteriormente, na década de 1940, com a proibição do trabalho de menores ${ }^{2-5}$. Entretanto, são poucos os dados e informações do período sobre o uso do benzeno no processo produtivo, a magnitude da exposição dos trabalhadores e os seus efeitos à saúde. No segundo ciclo, de 1960 a 1982, estudos revelam a grave situação de exposição dos trabalhadores ao benzeno e alertam sobre o perigo do seu uso industrial e doméstico. Nesse período foram realizadas análises para detectar a concentração de benzeno na composição de produtos ${ }^{2,3}$ e estudos hematológicos, que identificaram os primeiros casos de aplasia de medula ${ }^{6,7}$. No terceiro 
ciclo, de 1980 a 1990, foi priorizada a exposição ocupacional nas indústrias siderúrgicas, petroquímica e química de segunda geração. Porém, não há registro de estudo nacional de acompanhamento clínico e epidemiológico desses trabalhadores ${ }^{1}$. Existe uma casuística de 3 mil casos de intoxicação por benzeno, em sua maior parte identificado por sindicatos e serviços públicos de saúde ${ }^{5,8}$. O quarto período inicia em 1994, quando houve o reconhecimento do benzeno como substância cancerígena pelo Ministério do Trabalho, o que resultou na pactuação conhecida como Acordo do Benzeno ${ }^{9}$. Neste período, houve intensas regulamentações relacionadas principalmente à proibição da utilização do benzeno, permitindo seu uso apenas em alguns setores industriais; a adoção do conceito de Valor de Referência Tecnológico (VRT); a valorização da participação dos trabalhadores nas ações de prevenção de riscos. Apesar das importantes medidas em relação à restrição da exposição ao benzeno no período, não foram realizados estudos de monitoramento do efeito dessas mudanças nos ambientes de trabalho, o que permitiria avaliar o seu impacto na saúde dos trabalhadores. Após a década de 1990, persistiu um período de ausência de registros sobre a situação de saúde dos trabalhadores expostos que foi denominado de "silêncio epidemiológico do benzenismo"10.

Em 2005, iniciativas com propósito de ampliar as ações de vigilância para os PRC foram desenvolvidas pelo SUS em diversas regióes do país ${ }^{11}$. No que se refere à continuidade dos estudos e à necessidade de conhecer a magnitude da exposição ocupacional ao benzeno e seus efeitos à saúde no Brasil, em 2016, um estudo estimou que 770.212 trabalhadores foram expostos ao benzeno, uma prevalência ponderada por grupo ocupacional de $0,9 \%{ }^{12}$. Outro estudo, de $2017^{1}$, fez uma revisão de literatura identificando que ocorreram 3 mil casos de intoxicações por benzeno e malignidades linfo-hematopoiéticas relacionadas a essa exposição, entre 1996 e 2006. Essas iniciativas representam a continuidade do processo e a aplicabilidade do conhecimento científico acumulado dos períodos anteriores.

O benzeno é tema de interesse no âmbito ocupacional e ambiental em todo o mundo. Paradoxalmente, de um lado, apresenta importância como matéria-prima de larga utilização industrial, promovendo dependência da sociedade moderna aos produtos obtidos a partir de seus derivados; por outro lado, é objeto de controle mundial pelas suas características de toxicidade, que o colocam como contaminante universal com potenciais efeitos graves à saúde em relação à maioria dos demais hidrocarbonetos. Esse dilema produz conflitos de interesse que repercutem no sistema normativo de proteção social à saúde. Ao contrário do rigor da legislação e das esperadas medidas de proteção à saúde no trabalho, especialmente por tratar-se de um composto comprovadamente cancerígeno para o qual não há limite seguro de exposição, observa-se negligência com a aplicação de normas e de medidas de segurança e saúde nos ambientes de trabalho, o que pode levar à ampliação do adoecimento dos trabalhadores.

Os trabalhadores de PRC estão expostos a diferentes solventes presentes nos diversos tipos de combustíveis comercializados (gasolina, etanol, diesel, biodiesel, gás natural veicular), além da poluição ambiental, já que o trabalho ocorre em ambientes abertos. O processo de trabalho em postos de combustíveis envolve múltiplas atividades. Algumas ocasionam maior exposição por propiciar contato direto com essas substâncias, como abastecimento de veículos, descarregamento de caminhões-tanque, testes de controle de qualidade dos produtos fornecidos pelas distribuidoras, troca de óleo e de outros lubrificantes automotivos, lavagem de carros e de peças com combustíveis. Outras envolvem atividades administrativas e de atendimento aos clientes. Na maior parte dos PRC do país, os trabalhadores não utilizam equipamentos de proteção individual ou coletiva durante a jornada de trabalho; além disso, não há equipamentos individuais que evitem a absorção por todas as vias de exposição (dérmica, respiratória e oral) e os sistemas de recuperação dos vapores ainda são de uso incipiente no Brasil.

Nesse contexto histórico e científico, as publicações deste suplemento da RBSO lançam mão de diferentes áreas do conhecimento para mostrar a situação da exposição ao benzeno nos trabalhadores em PRC e descrever experiências de ações de controle desenvolvidas no Brasil. Para tanto, utilizaram-se diversas abordagens metodológicas, de disciplinas das ciências sociais, da clínica e da toxicologia. A linha comum dos manuscritos é a atualização do estado da arte do conhecimento sobre a exposição ao benzeno e as modalidades de intervenção no cenário atual da proteção legal e institucional à saúde dos trabalhadores.

Duas Revisões abordaram os principais biomarcadores de genotoxicidade e expressão gênica para avaliação de trabalhadores de postos de combustíveis expostos a vapores da gasolina, assim como metodologias baseadas na cromatografia e na espectrometria de massas para a determinação do ácido $S$-fenilmercaptúrico como biomarcador de exposição ao benzeno. Esses manuscritos apresentam métodos analíticos e técnicas para o uso de biomarcadores de efeito, exposição e suscetibilidade, que são utilizados para avaliar e identificar potenciais danos à saúde. 
Para melhor compreensão do metabolismo do benzeno e dos seus metabólitos empregados como biomarcadores, foi inserida uma Nota ao dossiê, que também discutiu os conflitos de interesse relacionados à interpretação desses biomarcadores, uma vez que, como não há concentração-limite segura de exposição ao benzeno, por se tratar de um composto comprovadamente genotóxico e cancerígeno ${ }^{13}$, também não há limite seguro para seus metabólitos, que devem se apresentar zerados nos exames de biomarcadores de efeito dos trabalhadores ${ }^{14}$, em prol da defesa da saúde do trabalhador.

Dois Artigos publicados apresentaram resultados de avaliação da exposição ocupacional ao benzeno presente na gasolina utilizando biomarcadores de genotoxicidade, como teste cometa em comparação ao ácido trans,trans-mucônico urinário $(A t t \mathrm{M})$ em indivíduos expostos ocupacionalmente ao benzeno em PRC das cidades de Ibirité e Contagem, na região metropolitana de Belo Horizonte/MG, e para avaliar danos genotóxicos na exposição ao BTEX (benzeno, tolueno, etilbenzeno e xilenos) em trabalhadores de diferentes postos de combustíveis da Zona Norte do município do Rio de Janeiro/RJ.

Nos Ensaios publicados, os autores buscaram trazer contribuições acerca de: normas e aspectos toxicológicos de exposição ocupacional e ambiental ao benzeno e avaliação de risco; ações potenciais dos serviços em saúde em relação à vigilância sanitária a partir da aplicação do modelo Força-Motriz/Pressão/Situação/ Exposição/Efeito/Ação (FPSEEA); avaliação clínico-laboratorial baseada na análise de hemograma para o estabelecimento de critérios de classificação da exposição e dos trabalhadores expostos, para orientar a conduta dos profissionais de saúde.

Por fim, na seção Relatos de experiência, os serviços públicos - Cerest - descreveram as diversas experiências de Vigilância em Saúde do Trabalhador no SUS, com abrangência nos estados do Espírito Santo, Santa Catarina e nos municípios de Campinas/SP, Santa Cruz do Sul/RS e Itaberaba/BA, que juntos evidenciam a contínua exposição dos frentistas e dos demais trabalhadores em PRC e a baixa aplicação das normas. Também evidenciaram a consolidação da rede de vigilância da exposição ao benzeno pela articulação dos grupos de técnicos e trabalhadores, estratégias de intervenção direcionadas aos PRC e unificação de instrumentos de inspeção, a exemplo do roteiro de inspeção.

No Brasil, apesar das evidências científicas que apontam a exposição ocupacional ao benzeno como uma das potenciais causas pelo aparecimento de alterações hematológicas, carcinogenicidade e genotoxicidade, mesmo em baixas concentrações, como é o caso dos postos de combustíveis, ainda persistem questionamentos técnicos e políticos a respeito da confiabilidade das técnicas analíticas e, portanto, da própria exposição; questionamento este que não é isento de conflitos de interesse. Além de mostrar parte dos estudos brasileiros que se contrapõe a essas afirmativas, este dossiê visa também trazer ao debate novos estudos internacionais, que comprovem que o benzeno é facilmente absorvido, amplamente distribuído e metabolizado, produzindo uma complexidade de metabólitos eletrofílicos e hematotóxicos, através de várias vias em diversos tecidos, incluindo a medula óssea, o que resulta no seu efeito carcinogênico, como discutido em recente Monografia do Benzeno, que será publicada no volume 120 das IARC Monographs ${ }^{15}$, que contou com a participação de representantes brasileiros da Fiocruz e do Instituto Nacional do Câncer (INCA) envolvidos na temática. Os estudos mostraram que o benzeno é ativado metabolicamente, é genotóxico, imunossupressor e induz estresse oxidativo, danos oxidativos e quebras no DNA, aberrações cromossômicas e micronúcleos em populações expostas $^{15}$. Portanto, a exposição a esse composto nos processos de trabalho em PRC implica atividade de risco, pois os trabalhadores entram em contato direto com os vapores de combustíveis.

Esperamos, assim, que o esforço em produzir este dossiê temático contribua com dados nacionais de exposição ocupacional ao benzeno no âmbito dos campos de interesses acadêmicos, dos trabalhadores, dos movimentos sociais e do poder público, integrando iniciativas e saberes, que qualificam a investigação, a identificação e o monitoramento da exposição a esse carcinógeno, na perspectiva de efetivar mudanças na organização e nos ambientes de trabalho e, consequentemente, prevenir os seus efeitos potencialmente adversos à saúde dos trabalhadores.

\section{Agradecimentos}

Aos editores da RBSO, Eduardo Algranti, Eduardo Garcia Garcia, Cézar Akiyoshi Saito e Albertinho Carvalho (editor convidado) pela condução de todo o processo de construção deste dossiê, sem os quais não seria possível alcançar os resultados esperados. A elaboração deste dossiê exigiu reconhecimento sobre o estado da arte da produção do conhecimento sobre a exposição ao benzeno e seus efeitos à saúde, à luz de 
recentes evidências científicas, tanto em nível nacional como internacional, o que demandou momentos de consensos e esclarecimentos durante o processo de sua produção.

A Danilo Fernandes Costa, do Ministério do Trabalho, Superintendência Regional do Trabalho e Emprego no Estado de São Paulo, e a Arline Sydneia Abel Arcuri (Fundacentro/São Paulo), pelas contribuições e leitura crítica deste editorial.

\section{Referências}

1. Costa DF, Goldbaum M. Contaminação química, precarização, adoecimento e morte no trabalho: benzeno no Brasil. Ciênc Saúde Coletiva [Internet]. 2017 [acesso 2017 out 15];22(8):2681-92. Disponível em: http://www. scielo.br/scielo.php?script $=$ sci_arttext\&pid $=$ S1413-81232017002802681\&lng $=$ pt

2. Novaes TCP. Bases metodológicas para abordagem da exposição ocupacional ao benzeno [dissertação]. São Paulo: Universidade Federal de São Paulo; 1992.

3. Carvalho AB, Arcuri A, Bedrikow B, Augusto LG, Oliveira LC, Bonciani M, et al. Benzeno: subsídios técnicos à Secretaria de Segurança e Saúde no Trabalho (SSST/MTb). 2. ed. São Paulo: Fundacentro; 1995.

4. Freitas N, Arcuri SA. O benzeno e a saúde dos trabalhadores: a luta histórica e a negociação tripartite. In: Bonciani M, organizador. Saúde, ambiente e contrato coletivo de trabalho: experiências em negociação coletiva. São Paulo: LTr Editora; 1996. p. 71-117.

5. Magrini RO. Novas relações trabalhistas de segurança e saúde do trabalhador desenvolvidas no estado de São Paulo e no Brasil [tese]. São Paulo: Universidade de São Paulo; 1999.

6. Wakamatsu CT. Contribuição ao estudo da exposição profissional ao benzeno em trabalhadores de indústrias de calçados [dissertação]. São Paulo: Universidade de São Paulo; 1976.

7. Wakamatsu C, Fernicola N. Intoxicação profissional por benzeno. In: Mendes R. Medicina do trabalho e doenças profissionais. São Paulo: Savier; 1980.

8. Augusto L, Novaes T. Ação médico-social no caso do benzenismo em Cubatão, São Paulo: uma abordagem multidisciplinar. Cad Saúde Pública (online). 1999;15(4):729-38.

9. Arcuri AS, Cardoso LMN, organizadores. Acordo e legislação sobe o benzeno: 10 anos. São Paulo: Fundacentro; 2005.

10. Moura-Correa MJ. A construção social do silêncio epidemiológico do benzenismo: uma história negada. Porto Alegre [dissertação]. Porto Alegre: Pontifícia Universidade Católica do Rio Grande do Sul; 2008.

11. Moura-Correa MJ, Jacobina AJR, Santos SA, Pinheiro RC, Menezes MAC, Tavares AM, et al. Exposição ao benzeno em postos de revenda de combustíveis no Brasil: Rede de Vigilância em Saúde do Trabalhador (Visat). Ciênc Saúde Coletiva [Internet]. 2014 [acesso 2017 out 15];19(12):4637-48. Disponível em: http://www.scielo. $\mathrm{br} /$ scielo.php?script $=$ sci_arttext\&pid $=$ S1413-81232014001204637\&lng $=$ en

12. Moura-Correa MJ, Santana VS. Exposição ocupacional ao benzeno no Brasil: estimativas baseadas em uma matriz de exposição ocupacional. Cad Saúde Pública [Internet]. 2016 [acesso 2017 out 27];32(12):e00129415. Disponível em: http://www.scielo.br/scielo.php?script=sci_arttext\&pid=S0102-311X2016001205004\&lng=en

13. World Health Organization (WHO). International Agency for Research on Cancer. Chemical agents and related occupations. Lyon: WHO; 2012.

14. Arcuri ASA, Costa DF, Possebon J, Kanasawa KC, Tardini LIN, Constantino L, et al. Efeitos da exposição ao benzeno para a saúde. São Paulo: Fundacentro; 2012. (Série Benzeno. Fascículo 1).

15. Dana L, Kathryn ZG, Yann G, Fatiha ElG, Véronique B, Lamia B-T, et al. Carcinogenicity of benzene. Lancet Oncol (online) [Internet]. 2017 [acesso 2017 out 15]. Disponível em: http://www.thelancet.com/journals/lanonc/ article/PIIS1470-2045(17)30832-X/abstract 